\title{
La narrativa checa en España desde 1975: presencias y ausencias*
}

\section{Czech Narrative Published in Spain after 1975: Presences and Absences}

\author{
Luis Pegenaute \\ Universitat Pompeu Fabra \\ luis.pegenaute@upf.edu
}

Recibido agosto-2019. Revisado: octubre-2019. Aceptado: noviembre-2019.

Resumen: En este trabajo prestaremos atención a la traducción de narrativa checa (de expresión checa) publicada en España desde 1975, señalando también algunas ausencias relevantes. Tras la Primavera de Praga en 1968 y la restauración de la democracia en España, se comenzaron a publicar en España numerosas obras checas, en particular de un "clásico», como Karel Čapek y de autores contemporáneos, ya fueran exiliados o disidentes como Pavel Kohout, Zdena Salivarová, Ota Filip, Iva Procházková, Josef Škvorecký, Ivan Klíma o Daniela Hodrová. Es en la primera mitad de los años 80 cuando empieza a darse un auténtico interés por esta literatura. Si en el ámbito de la poesía el interés vino propiciado por la fascinación que Clara Janés sentía por Vladimir Holan y la concesión del Premio Nobel de literatura en 1984 a Jaroslav Seifert, en el ámbito específico de la prosa el interés vino despertado por el reconocimiento a nivel mundial de la obra de Milan Kundera. Aunque cabe destacar también a otros autores, como Bohumil Hrabal o Jiř́ Weil, este último llegó con mucho

* Este trabajo se ha realizado en el marco del proyecto de investigación Portal digital de Historia de la Traducción en España, PGC2018-095447-B-I00 (MCIU/AEI/FEDER, UE).

LUis PEGENAUTE La narrativa checa en España desde 1975: presencias y ausencias 
retraso a España. En la literatura checa escrita con posterioridad a 1989 ha destacado la proliferación de diarios y memorias, así como de ficción posmoderna y de novela histórica, de obras feministas y de otras que han recreado el pasado reciente, con un flujo de traducciones desigual.

Palabras clave: España; traducción; checa; narrativa.

\begin{abstract}
Attention is paid to the translation of Czech narrative - written in Czech - published in Spain after 1975, pointing out some significant absences. After the Prague Spring in 1969 and the restoration of democracy in Spain, numerous Czech pieces of writing were translated, more in particular those by well known Karel Čapek and by some contemporary exiled or dissident writers, such as Pavel Kohout, Zdena Salivarová, Ota Filip, Iva Procházková, Josef Škvorecký, Ivan Klíma o Daniela Hodrová. It is in the first half of the 80s that a real interest in Czech literature arises. In the field of poetry, that was due to Clara Janés' fascination for Vladmir Holan and the award of the Nobel Prize in Literature to Jaroslav Seifert. In the field of prose, that was due Milan Kundera's achievement of worldwide recognition. Although some other writers, such as Bohumil Hrabal or Jiř Weil were also prominent, the latter was translated at a very late stage. Post-1989 Czech prose has been characterised by the proliferation of diaries and memories, by the production of postmodern fiction and historical novels, feminist pieces and by a number of attempts to recreate the recent past, all of which have been subjected to an uneven flux of translations.
\end{abstract}

Key words: Spain; Translation; Czech; Narrative.

\title{
1. OBJETIVOS Y RECOGIDA DE DATOS
}

En las páginas que siguen nos proponemos trazar una panorámica sobre la presencia de la narrativa checa en España a partir de 1975 a través de un análisis de la publicación de traducciones, lo que nos obligará a referirnos ocasionalmente a obras publicadas en el contexto original con anterioridad significativa sobre esta fecha ${ }^{1}$. Para ello, hemos consultado las referencias presentes en los catálogos de la Biblioteca Nacional de España y la Biblioteca de Catalunya, así como la Base de datos de libros editados en España (Agencia española del ISBN). Si bien todos los datos bibliográficos han sido recabados de esas fuentes, cabe mencionar también que contamos con otros recursos de documentación en forma de anexos a trabajos de investigación: así, Hermida de Blas y Gonzalo (2007, 196-202), sobre literatura checa traducida al catalán y al castellano; Cuenca $(2013,102-118)$, sobre literatura checa traducida al castellano

1. Sobre la literatura checa moderna y contemporánea, véanse, por ejemplo, Fialová (s. f.), French (1982), Hermida de Blas (1994, 331-366), Porter (2001) y Holý (2008).

LUis PEGENAUTE La narrativa checa en España desde 1975: presencias y ausencias
CLINA

vol. 5-2, December 2019, 121-146

elSSN: 2444-1961

Ediciones Universidad de Salamanca - CC BY-NC-ND 
y publicada en España entre 1939 y 2000; Schejbal y Utrera $(2004,56)$, sobre obras checas traducidas al catalán ${ }^{2}$. El análisis de la presencia de la narrativa checa en traducción nos ha permitido también identificar cuáles son las ausencias, las cuales se concentran, muy principalmente, en los autores más recientes.

Aunque no hemos efectuado un análisis de la literatura española traducida al checo, cabe decir que, según Hermida de Blas y Gonzalo $(2007,85)$, dicha literatura es mucho más conocida en el espacio checo de lo que lo es la literatura checa en el español, lo que dichos estudiosos atribuyen a las diferencias demográficas entre ambos países, a sus respectivas trayectorias históricas y al desconocimiento generalizado que en España ha habido de las culturas eslavas ${ }^{3}$. En sentido similar, Schejbal y Utrera $(2004,45)$ señalan que la literatura catana traducida al checo supera largamente a la literatura checa traducida al catalán, dándose en este caso un interés que se remonta a finales del siglo XIX y que se mantuvo vigente en el periodo totalitario a través de la editorial Odeon y la revista Svĕtová literatura. A pesar de estas discrepancias en los flujos de traducción, Cuenca (2013) encuentra una serie de similitudes en las circunstancias socioculturales de ambos espacios en la época contemporánea, con marcados paralelismos en sus modos de evolución y con diferencias de escasos años en los puntos más importantes de su devenir, el más importante de los cuales es el de la finalización de sus respectivos regímenes totalitarios en 1975 y $1989^{4}$.

\section{LA LITERATURA CHECA EN SU CONTEXTO HISTÓRICO}

La literatura checa de la posguerra está condicionada, evidentemente, por la situación política del país. Al finalizar el conflicto bélico, Checoslovaquia se instauró en la órbita de influencia soviética. Los comunistas tomaron el poder en febrero de 1948, un mes antes de la muerte, en extrañas circunstancias, del ministro moderado Jan

2. Además de las referencias citadas sobre la traducción y recepción en España de la literatura checa, véanse, por ejemplo, Zgustová (2002), Hermida de Blas (2003) y Hermida de Blas y Gonzalo (2009). Los dos últimos trabajos tratan también la literatura eslovaca.

3. Aunque Hermida de Blas y Gonzalo se refieren exclusivamente a la literatura española (y no en español), a la primera de estas circunstancias habría que sumar, claro está, el alto número de hispanohablantes en todo el mundo, con un potencial de producción literaria mucho más extenso que el de los escritores de expresión checa.

4. Así, si bien estos puntos de coincidencia se sitúan ya antes del periodo que a nosotros nos concierne, cabe señalar que «ambas naciones asisten a episodios de inestabilidad en el periodo de entreguerras, agresión bélica o injerencia de potencias extranjeras, instauración de regímenes totalitarios, penuria económica de posguerra, estabilización económica y social, intento de cambios sociopolíticos "desde dentro", agotamiento del régimen instaurado en la posguerra, transición pacífica a una democracia de corte liberal, integración en estructuras supranacionales occidentales (como la CEE/UE y la OTAN) y asimilación de la globalización» (Cuenca 2013, 91).

LUis PEGENAUTE La narrativa checa en España desde 1975: presencias y ausencias
CLINA

vol. 5-2, December 2019, 121-146

elSSN: 2444-1961

Ediciones Universidad de Salamanca - CC BY-NC-ND 
Masaryk. La República Socialista de Checoslovaquia se mantendría vigente hasta 1989. La censura mantuvo un estricto control hasta finales de los 50 , pero la relativa relajación alcanzó antes a la poesía que a la narrativa. La progresiva liberalización de los 60 permitió el surgimiento de voces nuevas en la narrativa, como Milan Kundera, Ivan Klíma, Pavel Kohout o Bohumil Hrabal. Durante los primeros meses de 1968 el país experimentó un proceso de liberalización política con la eleccion como Secretario General del Partido Comunista por parte del reformista Alexander Dubček, pero esta apertura -la Primavera de Praga- se vio violentamente truncada con la invasión de las fuerzas del Pacto de Varsovia en agosto de aquel año, lo que se conocería como Operación Danubio. Tal y como señala Hermida de Blas (1997, 352), la supresión de las libertades tras la Primavera de Praga reinstauró, de manera más radical, la adopción de tres formas de expresión literaria: la literatura autorizada para su publicación en el país, la literatura subversiva producida localmente y la del exilio. La caída del comunismo permitió la publicación por primera vez de numerosos autores exiliados o hasta entonces ilegales.

El final del dominio soviético no llegaría hasta finales de 1989, gracias a la transición pacífica desarrollada durante la que es conocida como la Revolución de Terciopelo, que culminó con la llegada de Václav Havel al poder. El final de la Guerra Fría y la disolución de países del bloque oriental como la URSS o Yugoslavia propició la escisión no violenta del antiguo Estado de Checoslovaquia en dos nuevas naciones, la República Checa y Eslovaquia, el 1 de enero de 1993. En los últimos años han destacado como figuras intelectuales de primer nivel escritores tan relevantes, y tan reconocidos, como Petr Šabach, Jáchym Topol, Miloš Urban, Patrik Ouředník o Petra Hůlová.

\section{LOS AUTORES MÁS CONSAGRADOS}

Tras la Primavera de Praga en 1968 y la restauración de la democracia en España, en los años 70 se comenzó a publicar un buen número de obras checoslovacas, en particular de un «clásico» como Karel Čapek (1890-1938) y de autores contemporáneos, ya fueran exiliados o disidentes. La producción teatral de Čapek, así como sus novelas de ficción científica se habían traducido desde época temprana y se siguieron traduciendo durante la época franquista, aunque a partir de lenguas intermedias, como el inglés o el alemán. Las primeras versiones directas, de la mano de Ana Orozco de Falbr (Anna Falbrová), se publicaron en los años 60 en Checoslovaquia. A partir de los años 70 se reeditaron en España: así, su colección de cuentos Apócrifos (M.: Felmar, 1974; M.: Valdemar, 2009), un conjunto de relatos por el que desfilan personajes históricos, bíblicos o ficticios, como Prometeo, Alejandro Magno, Arquímedes, Lázaro, 
Pilatos, Don Juan, Atila, Hamlet o Napoleón ${ }^{5}$. También es de Orozko de Falbr la traducción de una selección de cuentos reeditada años más tarde con el título de uno de ellos, La confesión de Don Juan (Madrid: Compañía Europea de Comunicación e Información, 1992), así como la de su novela más conocida, La guerra de las salamandras (B.: Bruguera, 1982; M.: Hiperión, 1992; B.: Gigamesh, 2003, 2009; Santa Cruz de Tenerife: Weston, 2015), una obra de ciencia ficción publicada en 1936 que satiriza el mapa político mundial en vísperas de la Segunda Guerra Mundial, criticando el nacionalismo y colonialismo francés e inglés, así como el supremacismo alemán. En ella, el descubrimiento de una nueva especie de salamandras en el océano Pacífico lleva a su explotación como mano de obra, tras descubrir en ellas atisbos de inteligencia. Progresivamente, van adquiriendo el conocimiento de los humanos y creciendo en población hasta que se rebelan, estableciendo una lucha mundial por el control de la tierra. De esta novela encontramos también versiones de José Diéguez (M.: Doncel, 1972) y, más tarde, de Luz Monteagudo (B.: Books4pocket, 2008), además de la publicada originalmente en 1945, en versión de Carmen Díez de Oñate y Mildred Forrester a partir del inglés, con el título de Guerra con las salamandras (M.: Revista de Occidente). De la obra teatral R.U.R. contamos con una traducción realizada por Consuelo Vázquez de Parga a partir del inglés y que se ha publicado suelta o en combinación con otras piezas: R.U.R. y El juego de los insectos (M.: Alianza Editorial, 1966); RUR / La fábrica de Absoluto (B.: Minotauro, 2003); RUR: Robots Universales Rossum (B.: Círculo de Lectores, 2004). También la versión libre de Juan Cervera: R.U.R. (Robots Universles Rossum) (M.: Escuelas Profesionales Sagrado Corazón, 1971). Las experiencias de su recorrido por nuestro país en 1930 son recogidas en Viaje a España (M.: Hiperión, 1989) por Clara Janés y Jana Stancel. De su obra para lectores infantiles y juveniles se han traducido La princesa de Solimania (M.: SM, 1985), por Marinella Terzi a partir del alemán, y Nueve cuentos y uno de propina (M.: Siruela, 1993, 2003), por Jitka Mlejnkova y Alberto Ortiz. La Trilogía noética ha sido traducida recientemente por Patricia Gonzalo de Jesús para la editorial cordobesa El Olivo Azul: La kratatita: una fantasía nuclear (2010), El meteorito (2011), Hordubal (2011). Su visión de la Inglaterra de los años 20 quedó reflejada en Cartas inglesas (Sevilla: Renacimiento, 2014), por Helena Voldanova. Su peculiar y poético estudio sobre la jardinería ha sido traducido como El año del jardinero (Palma de Mallorca: José J. de Olañeta, 2009) por Esteve Serra. Es esta la única obra de Čapek traducida al gallego: $O$ ano do xardineiro (Cangas: Rinoceronte, 2009), por Fernado de Castro. En catalán contamos con Contes d'una butxaca (Sant Boí de Llobregat, 1982) y D'una butxaca i de l'altra: Contes (B.: Edicions 62, 1991), por Monika Zgustová, y con La guerra de les salamandres (B.: Proa, 1998; B.: Males herbes, 2016), por Núria Mirabet, quien también se ha ocupado de R.U.R.

5. En la relación de traducciones solo indicaré la ciudad de publicación la primera vez en que aparezca mencionada la editorial en cuestión.

Luis PEGENAUTE La narrativa checa en España desde 1975: presencias y ausencias 
(2017) para esta última editorial. Ambas han sido prolificas traductoras de literatura checa al castellano y catalán. Al euskera solo se ha traducido R.U.R. (Bilbao: Mensajero, 1991), por Xabier Monastero.

De la que probablemente es la novela checa más famosa, la inmortal obra satíica de Jaroslav Hašek (1883-1923), que no pudo llegar a completar debido a su prematura muerte con solo cincuenta años de edad, no tuvimos versión española hasta 1980, con el título de Las aventuras del valeroso soldado Svejk (B.: Destino), en versión realizada por Alfonsina Janés a partir del alemán ${ }^{6}$. La novela, en gran medida autobiográfica, narra las desquiciantes peripecias de un soldado checo durante el primer año de la Primera Guerra Mundial. Hubo que esperar al siglo XXI para contar con versiones directas, pero llegaron por partida triple: Las aventuras del buen soldado Svejk (Hondarribia: Hiru, 2000; B.: Galaxia Gutenberg, 2008), por M. Zgustová; Las aventuras del valiente soldado Svejk (B.: Books4pocket, 2009), por Luz Monteagudo y Los destinos del buen soldado soldado Svejk durante la primera guerra mundial (B.: Acantilado, 2016), por Fernando de Valenzuela. Este último ha sido uno de los más conspicuos traductores de literatura checa en castellano. En catalán existe traducción de M. Zgustová, Les aventures del bon soldat Svejk (B.: Proa, 1995) y en euskera, de Karlos Cid, Xveik soldadu onaren menturak (Amorebita: Ibaizabal, 1992).

Otro escritor muy difundido entre nosotros ha sido Bohumil Hrabal (1914-1997), autor de una sesentena de libros que incluye colecciones de relatos y novelas, varios de los cuales han sido llevados al cine con gran éxito (como, por ejemplo, Trenes rigurosamente vigilados, que, bajo la dirección de Jiři Menzel, obtuvo en 1966 el Óscar a la mejor película extranjera). Como tantos otros intelectuales, también él fue represaliado por las fuerzas soviéticas; en su caso, por haberse adherido al llamado «Manifiesto de las dos mil palabras» que había promovido Ludvík Vaculík. Como consecuencia, su obra hubo de distribuirse en Checoslovaquia en ediciones samizdat, es decir, copia y distribución clandestina de literatura prohibida por el régimen soviético. Hrabal fue un escritor atípico, pues si bien practicó la poesía en los años 30 y 40, no se dedicó profesionalmente a la literatura hasta la publicación de Skřivánci na niti [Alondras en el alambre, 1963], cuando ya estaba a punto de cumplir los cincuenta años de edad. Su obra está protagonizada por hombres y mujeres con los que los lectores se identifican fácilmente y su trama argumental muchas veces gira en torno a situaciones cotidianas que son tratadas con humor, haciéndonos apreciar que no son solo anodinas, sino también absurdas. En 1993, Hrabal obtuvo el Premio Jaroslav Seifert de literatura, el galardón checo más prestigioso, por su trilogía Bodas en casa, una suerte de autobiografía novelada cuya redacción finalizó en 1984, pero que no llegó a ser publicada en

6. Vavroušová (2016) analiza la respuesta de la censura española a esta obra, y también a otras obras checas de literatura infantil y juvenil (tres de Jan Prochászka, dos de Ota Hofman, dos de Ota Filip y una de Pavel Kohout), traducidas al castellano a través de versiones alemanas.

Luis PEGENAUTE La narrativa checa en España desde 1975: presencias y ausencias
CLINA

vol. 5-2, December 2019, 121-146

elSSN: 2444-1961

Ediciones Universidad de Salamanca - CC BY-NC-ND 
Checoslovaquia hasta 1992, como consecuencia de la censura. La obra de Hrabal ha sido distribuida con bastante éxito en España. Su primera aparición en castellano fue la traducción de la novela Trenes rigurosamente vigilados (Santiago de Chile: Editorial Santiago, 1969), por traductor desconocido. Hubo que esperar hasta la traducción de F. Valenzuela (B.: Península, 1988) para que se distribuyera en España esta obra, una divertida historia sobre la resistencia, protagonizada por los empleados de la estación de tren de un pequeño pueblo checoslovaco durante la invasión alemana en la Segunda Guerra Mundial. Otra de las obras más conocidas de Hrabal, también llevada al cine por Menzel, es Yo que he servido al rey de Inglaterra, traducida por primera vez por J. Mlejnková y A. Ortiz (Destino, 1989) y, posteriormente, con el título de Yo serví al rey de Inglaterra, por M. Zgustová (Galaxia Gutenberg, 2011). Se trata de una narración en primera persona que tiene mucho de fábula moral y en la que se nos relatan, muchas veces en clave de humor, los intentos de ascender socialmente por parte de un joven aprendiz de camarero de hotel. Zgustová también se ha ocupado de otra de las obras capitales de Hrabal, Una soledad demasiado ruidosa (Destino, 1990), novela breve en la que se describe la existencia, un tanto anodina, de un hombre de ya avanzada edad cuyo trabajo consiste en triturar papel. Mientras el protagonista deambula por Praga, reflexiona sobre las enseñanzas de los grandes artistas, sobre el amor y la soledad, sobre la creación y el paso del tiempo. También ha traducido para Destino Personajes en un paisaje de infancia (1991), en la que se dibuja la vida de una pequeña ciudad de Bohemia a través de las peripecias de una joven pareja y los clientes de su cervecería; Quién soy yo (1992), colección de siete meditaciones autobiográficas; la ya referida Bodas en casa (1993), en la que el propio Hrabal se muestra a sí mismo a través de la voz de su esposa, en un arriesgado ejercicio literario que desafía las leyes de la autobiografía; La pequeña ciudad donde el tiempo se detuvo (1995), en la que un niño nos habla de la vida cotidiana de una pequeña urbe checa y sus habitantes, principalmente del carismático tío Pepin, un hombre vividor (y bebedor) que protagoniza otras obras de Hrabal; Mi gato Autičcko (Galaxia Gutenberg, 2016), una fábula sobre la obsesión y el sentimiento de culpa que, de nuevo, ubica al propio autor en el centro de la narración. Otras traducciones de este autor son, por ejemplo, la colección de relatos Anuncio de una casa donde ya no quiero vivir (Península, 1989), por C. Janés y J. Stancel; Las desventuras del viejo Werther (Península, 1994), por María García Barris; Los palabristas (Destino, 1997), por Eva Kruntorádová y N. Mirabet; Leyendas y romances de ciego (Destino, 2000), por Luisa Rancaño y N. Mirabet; Lecciones de baile para mayores (M.: Metáfora, 2003), por J. Mlenjková y A. Ortiz. En catalán contamos con las traducciones que M. Zgustová ha hecho para la editorial Destino: Jo he servit el rei d'Anglaterra (1989), La petita ciutat on es va aturar el temps (1995), Personatges en un paisatge d'infància (1991) y Qui sóc jo (1992), además de Una solitud massa sorollosa (1989), Anunci d'una casa on ja no vull viure (1990), Noces a casa. Vita nuova. Terra erma (1993), para Edicions 62, y El meu gat Autíčko (1983), para Galàxia Gutenberg. Otras

LUIS PEGENAUTE La narrativa checa en España desde 1975: presencias y ausencias
CLINA

vol. 5-2, December 2019, 121-146 elSSN: 2444-1961

Ediciones Universidad de Salamanca - CC BY-NC-ND 
traducciones de Hrabal han sido, por ejemplo, Els sofriments del vell Werther (1993) y Trens rigorosament vigilats (Edicions 62, 1996), por María García Barris; Els enraonaires (1997), por N. Mirabet, y E. Kruntorádová, y Llegendes i romanços de cec (2000), por N. Mirabet y L. Rancaño, en ambos casos para Destino. En gallego, F. de Castro García ha traducido Unha soidade demasiado ruidosa (2006) y Eu servin ao rei de Inglaterra (2008) para la editorial Rinoceronte. En euskera, Fernando Rey Escalera se ha ocupado de Zorrotz begiratutato trenak (2002) para la editorial donostiarra Elkarlanean.

El más conocido de los escritores checos es, por supuesto, Milan Kundera (1929), quien ha residido en Francia desde 1975, tras presenciar la prohibición de sus obras en su país a partir de 1970. Adquirió la nacionalidad francesa en 1981. Progresivamente abandonó la escritura en checo para pasar a cultivarla en francés, tras haberse ocupado él mismo de revisar las traducciones de sus obras en esta lengua. Su obra ha sido publicada en numerosas ocasiones por la prestigiosa editorial francesa Gallimard. Si bien a partir de la caída del régimen comunista en 1989 no había motivo para que Kundera tuviera que ser leído en su propio país a través de traducciones, lo cierto es que a finales de la década de los 90 tan solo tres de las seis novelas que había escrito en checo se habían publicado en la República checa, lo que Kundera atribuyó a que no tenían todavía una forma definitiva. Michelle Woods (2001, 2006), por su parte, en sus estudios sobre la relación entre original y traducción en la obra de ficción de Kundera defiende que en las novelas que escribió en checo todo es, en realidad, traducción, y que la versión original ha sido transformada, en parte como consecuencia de su traducción al francés y al inglés. En su opinión, Kundera se ocupó de reescribir sus originales checos, introduciendo en estos textos intervenciones y alteraciones que habían surgido en las traducciones, lo que hace que, a pesar de la insistencia de Kundera en lograr que las traducciones se adhirieran a un alto grado de fidelidad al original, en realidad lo que las traducciones logran es desplazar al original, pues para Kundera el texto definitivo no es el texto primigenio, sino el de la versión más reciente. Entre otros premios y distinciones, ha sido merecedor del Premio de la Commonweath, otorgado en 1981 por el gobierno estadounidense; el Premio Jerusalén por la Libertad en 1985; el Premio de Literatura Europea, otorgado por el Estado austriaco en 1987; el Premio Internacional Herder en 2000; el Premio de Literatura del Estado checo en 2007 y el Premio de la Biblioteca Nacional de Francia en 2012. Su nombre ha sonado en numerosas ocasiones como candidato al Premio Nobel. En su producción literaria se dejan sentir influencias tan relevantes como las de Boccaccio, Rabelais, Cervantes, Sterne o Diderot, pero también de Musil, Gombrowitz, Broch, Kafka, Nietzsche o Heidegger. La primera de sus obras en ser traducida fue La broma (Plaza \& Janés, 1970), por Luis Guzmán desde el francés. Esta novela volvería a ser traducida en dos ocasiones: así, por F. Valenzuela (B.: Seix Barral, 1984) y por Paloma Rancaño y Sergi Rover (B.: Libros y Publicaciones Periódicas, 1985). Se trata de su primera novela, en la que, mediante el retrato de la vida privada de varios ciudadanos checoslovacos, presenta

Luis PEGENAUTE La narrativa checa en España desde 1975: presencias y ausencias
CLINA

vol. 5-2, December 2019, 121-146

elSSN: 2444-1961

Ediciones Universidad de Salamanca - CC BY-NC-ND 
una sátira de la represión totalitaria de la Unión Soviética tras la invasión de 1968. F. Valenzuela ha sido quien con mayor frecuencia ha vertido su producción escrita en checo: así, La vida está en otra parte (Seix Barral, 1979), su segunda novela, que se publicó antes en francés que en checo y que consiste en un retrato satírico del poeta ficticio Jaromil; El libro de la risa y el olvido (Seix Barral, 1982), una colección de siete narraciones sobre la oposición al régimen comunista; La insoportable levedad del ser (B.: Tusquets, 1985), su obra más conocida, que fue llevada al cine por Philip Kaufman y en la que retrata la vida intelectual de su país, desde la Primavera de Praga hasta los años posteriores a la invasión por parte del Pacto de Varsovia, a través de las vivencias de dos parejas, presentando una alternativa existencial al concepto del eterno retorno desarrollado por Nietzsche; La despedida (B.: Círculo de Lectores, 1987), en la que describe el encuentro de ocho personas en un balneario, cuyas circunstancias vitales acaban convergiendo; El libro de los amores ridículos (Tusquets, 1987), conjunto de narraciones escritas entre 1959 y 1968 por las que desfilan personajes hedonistas, poco habituales en el resto de su produccion literaria; La inmortalidad (Tusquets, 1990), su última novela escrita en checo que cierra una trilogía, junto a El libro de la risa y el olvido y La insoportable levedad del ser. De su obra francesa se ha ocupado Beatriz de Moura, amiga de Kundera y fundadora de la editorial Tusquets, en la que también han aparecido Los testamentos traicionados (1993), un ensayo en forma de novela en el que aparecen personajes como Stravinski, Kafka, Max Brod, Hemingway, Rabelais, etc.; La lentitud (1995), novela en la que se entremezclan personajes del pasado y del presente y en la que Kundera defiende que «hay un secreto lazo entre la lentitud y el recuerdo, entre la velocidad y el olvido»; La identidad (1988), una novela ambientada en París en la que realiza una indagación sobre la pareja y sobre la incertidumbre del amor ajeno; La ignorancia (2000), cuyo argumento gira en torno a una mujer y un hombre que se encuentran por casualidad durante su viaje de regreso al país natal del que emigraron veinte años atrás y que, por deseo expreso de Kundera, se publicó en castellano con anterioridad a la publicación del original francés; El telón (2005), un ensayo en el que revisa algunos «detalles existenciales» de diversas novelas capitales de la tradición europea; finalmente, La fiesta de la insignificancia (2014), una obra de trama mínima que, en palabras de Rafael Narbona en El cultural (05-09-2014), es «novela, pero también ensayo, introspección y teología» y que, en su opinión, constituye «una magnífica comedia que nos deslumbra con su exaltación de la vida y su ironía sobre las diferentes facetas del ser humano, que ama sin saber por qué, desea sin entender qué le mueve y espera sin albergar ninguna certeza». Previamente, también en Tusquets, se habían publicado la obra de teatro Jacques y su amo (1986), por Enrique Sordo, y la colección de ensayos El arte de la novela (1987), por F. Valenzuela y María Victoria Villaverde. En catalán, Kundera ha sido traducido, principalmente, por M. Zgustová: así, La insostenible lleugeresa del ser (Destino, 1987), Amors ridículs (Destino, 1987), El llibre de riure i de l'oblit (Cercle de lectors, 1989), El vals de l'adéu

Luis PEGENAUTE La narrativa checa en España desde 1975: presencias y ausencias 
(Destino, 1989) y La immortalitat (Destino, 1990). Paloma Rancaño se ocupó de La broma (B.: Edicions del 84, 1985) y Carme Geronès y Carles Urritz de Els testaments traïts (Destino, 1994). Desde el francés, Joan Tarrida i Planas tradujo L'art de la novela (Destino, 1987) y Jacques i el seu amo (B.: Edicions del Mall, 1987); Lluís Maria Todó, La identitat (Destino, 1998) e Imma Monsó, La ignorancia (Tusquets, 2002). En euskera contamos con Amodio barregarriak (Donostia: Erein Argitaletxea, 1993), Izatearen arintasun jasanezina (Irún: Alberdania, 2009), traducidas por K. Cid desde el checo y con Jacques eta Nagusia (Zarautz: SUSA, 1991), traducida por Beatriz Zabalaondo desde el francés.

\section{AUTORES DISIDENTES}

Es en la primera mitad de los años 80 cuando en España empieza a darse un auténtico interés por la literatura checa. Tal y como señalan Hermida de Blas y Gonzalo (2007, 189-190; 2009, 219), en el ámbito de la poesía esto vino propiciado por dos fenómenos: por una parte, por la fascinación que Clara Janés, la famosa escritora, poeta y miembro de la Real Academia Española, sentía por el poeta Vladimir Holan (19051980); por otra, por la concesión del Premio Nobel de literatura en 1984 a Jaroslav Seifert (1901-1986) $)^{7}$. En el ámbito específico de la prosa, como se ha señalado, el interés vino despertado por el reconocimiento a nivel mundial de la obra de Milan Kundera, particularmente tras la publicación de La insoportable levedad del ser. Sin embargo, en los años 70 ya se había comenzado a traducir a diversos autores autores disidentes y exiliados, como Ota Filip, Pavel Kohout, Zdena Salivarová y Jan Procházka. Posteriormente, a mediados de los 80, llegó otro autor perseguido, Josef Škvorecký. Más tarde, en los 90 lo hicieron Iva Procházková, Ivan Klíma, Jaroslav Putík o Daniela Hodrová y, mucho tiempo después, en la década actual y, por consiguiente, con gran retraso, Jiř́ Weil y Heda Margolius Kovály.

El periodista y novelista O. Filip (1930-2018) se exilió en Alemania en 1974 (donde se le concedió la nacionalidad tres años más tarde), tras haber sufrido encarcelamiento en su país entre 1969 y 1971 y ver cómo sus obras eran censuradas o prohibidas. Filip,

7. Janés descubrió a Holan a través de la lectura de la traducción de Hamlet y otros poemas (B., 1970), hecha por Josef Forbelský en colaboración con Guillermo Carnero. El descubrimiento de esta poesía le llevó a aprender checo y establecer contacto con el autor, con quien mantuvo una estrecha relación. Desde 1980, Janés ha vertido al castellano buena parte de la producción de Holan. Cabe señalar que en 1997 obtuvo el Premio Nacional de Traducción por el conjunto de su obra traductora. Los prólogos a estas traducciones, en los que la poeta y traductora interpreta la poesía de Holan, han nutrido la obra El espejo de la noche (2005). Por otra parte, la influencia de Holan se ha dejado sentir particularmente en algunas de sus propias obras, como Kampa (1986) y La voz de Ofelia (2005).

Luis PEGENAUTE La narrativa checa en España desde 1975: presencias y ausencias
CLINA

vol. 5-2, December 2019, 121-146

elSSN: 2444-1961

Ediciones Universidad de Salamanca - CC BY-NC-ND 
cuya trayectoria literaria se desarrolló en checo y alemán, fue merecedor del Premio Adelbert von Chamisso -concedido por el gobierno alemán a los escritores que no cuentan con el alemán como lengua materna- y recibió la Medalla Nacional al Mérito en las Bellas Artes del gobierno checo en 2012, a pesar de que su integridad moral se puso en entredicho al descubrirse en Praga en 1997 unos documentos que propiciaron la sospecha de que Filip había desarrollado actividades para el Servicio Secreto (StB), la policía de Seguridad del Estado que estuvo operativa entre 1945 y 1989. Plaza \& Janés publicó dos novelas de Filip: El café de la calle del cementerio (1970), por Martín Ezcurdia, y Un loco para cada ciudad (1972), por José Manuel Pomares, a partir del alemán. En la primera de ellas, su ópera prima, describe las reflexiones de un joven sobre los sucesos acontecidos en Ostrava y norte de Moravia al finalizar la Segunda Gurra Mundial. En la segunda, al igual que en otras obras suyas como Zweikämpfe [Duelos, 1975] o Maindacht [Vigilia de mayo, 1977], describe los rigores de la vida bajo el comunismo. No se ha traducido la que se suele considerar su aportación más importante, Nanebevstoupení Lojzka ze Slezské Ostravy [La ascensión de Lojka Lapáčka de Silesia Ostrava, 1974], la primera novela que escribió en el exilio y en la que describe la vida de los habitantes del norte de Moravia a lo largo de varias décadas.

Del poeta, dramaturgo y novelista P. Kohout (1928), que se exilió en Austria tras la Primavera de Praga y cuyas obras fueron prohibidas en su país, se tradujeron Cabeza abajo (B.: Pomaire, 1974), por Gregorio Vlastelica, una novela que hace uso de la fantasía para defender la resistencia individual frente al autoritarismo; La verduga (M.: UItramar, 1979), por Yolanda Salvá Yenes, una parábola absurda que denuncia el poder del autoritarismo, o El beso de Clara (Ultramar, 1982; B.: Salvat, 1987), por Sebastián Alemany a partir del alemán, sobre una adolescente clarividente. En 1990 se publicó su novela autobiográfica, en la que relata los acontecimientos vividos en torno a la Carta 77: ¿Dónde está el perro? (B.: Plaza \& Janés), por Julek Fuentes. En la primera década del 2000, F. Valenzuela tradujo para Alianza La hora estelar de los asesinos (2002), La larga ola tras la quilla (2003) y Mi mujer y su marido (2010).

Z. Salivarová (1933) se exilió en Toronto en 1969, donde impulsó, a través de la editorial Sixty-Eight, cofundada con su esposo, J. Škvorecký, la difusión en inglés de sus compatriotas represaliados. Hasta 1977 esta editorial fue propiedad de ambos cónyuges, pero con posteroridad pasó a ser una organización sin fines de lucro, bajo control público. Hasta 1993 llegó a publicar 227 títulos de autores predominanentemente exiliados o que solo habían logrado distribuir su oba en samizdat. La editorial barcelonesa Aymá publicó de Z. Salivarová sendas versiones, en catalán y castellano, de una de sus novelas, en ambos en casos en traducción de Jordi Arbonés: Estiu a Praga (1975) y Verano en Praga (1976). Tal y como se señaló en la anónima reseña de esta obra, publicada en El País (12-05-1976), el desarrollo de la novela «se halla salpicado de rasgos autobiográficos, situaciones vividas y en emociones sentidas, que la

LUis PEGENAUTE La narrativa checa en España desde 1975: presencias y ausencias
CLINA

vol. 5-2, December 2019, 121-146 elSSN: 2444-1961

Ediciones Universidad de Salamanca - CC BY-NC-ND 
convierten en un alegato y una exculpación a la vez que sirven para explicar su decisión de desarraigarse de su patria».

El escritor y guionista Jan Procházka (1929-1971) ocupó el cargo de vicepresidente de la Unión de Escritores Chescoslovacos entre 1968 y 1969, pero su trabajo fue prohibido al comienzo del periodo de «normalización» comunista. Varias de sus obras fueron ublicadas por Alfaguara: La carpa (1977), por el escritor chileno Antonio Skármeta; La república: Julina, yo y el final de la guerra (1979), por Lola Romero; El viejo y las palomas (1983), por Anton Dieterich; Viva Lenka (1985), por Javier Lacarra.

La obra de J. Škvorecký (1924-2012) comprende una quincena de novelas, una decena de colecciones de relatos y otros tantos ensayos, además de volúmenes de poesía y guiones de cine y televisión. También tradujo al checo a autores como E. Hemingway, W. Faulkner o H. James. Permaneció durante la mitad de su vida en Canadá, en compañía de su esposa, la ya mencionada Z. Salivarová. Fue galardonado con el Premio literario de la Unión de Escritores Checoslovacos en 1968, el Premio Internacional Neustadt en 1980, la Orden de Canadá en 1992 y la Orden del León Blanco de Checoslovaquia en 1990, además de haber sido nominado para el Premio Nobel en 1982. En castellano contamos con su primera novela, de tintes autobiográficos, Los cobardes (Alianza Editorial, 1990), traducida por Gian Castelli a partir del inglés, en la que Škvorecký introduce a su alter ego Smiřický, un fanático del jazz, como el propio autor. Este personaje volvería a aparecer en obras como El ingeniero de almas (B.: Circe, 1988), traducida por José Aguirre e Isabel Núñez. La afición de Škvorecký por el jazz también queda reflejada en El saxofón bajo (Alianza Editorial), en traducción de G. Castelli a partir del inglés. De esta obra existe traducción al catalán, El saxo baix (B., Proa, 1988), por M. Zgustová. También contamos con una sátira sobre los despropósitos censores de una editorial socialista, El pasado de Lenka Sliver (B.: Circe, 1990), por G. Castelli. Otra novela importante en su producción es El clan de los leones (B.: Dopesa, 1973), por Marinette Gasco Poy, en la que Škvorecký urde una ingeniosa trama en la que entremezcla una historia de amor, un misterioso asesinato y una sátira sobre la desintegración moral de la sociedad comunista en Checoslovaquia. En Las traiciones de todos los santos (B.: Duomo, 2011), por Rita da Costa a partir del inglés, describe, en tres estadios temporales, la situación de un grupo de antiguos compañeros de clase, los cuales intentar encontrar justificación a sus actos y su destino, amparándose en las circunstancias históricas y políticas de su entorno. En euskera se ha publicado Mundu mingotsa [Mundo amargo] (Irún: Alberdania, 1996), por K. Cid. No se ha traducido la que en ocasiones ha sido considerada su mejor novela, Mirákl [Milagro, 1972].

Iva Procházková (1953), hija del ya mencionado Jan Procházka, emigró en 1983 a Austria, si bien posteriormente se instaló en Alemania. En 1989 sus obras comenzaron a publicarse en Checoslovaquia, a donde regresó en 1994. En 2007 recibió el Premio Frederick Gerstacker, el más consolidado de todos los alemanes en lo que a literatura

Luis PEGENAUTE La narrativa checa en España desde 1975: presencias y ausencias
CLINA

vol. 5-2, December 2019, 121-146

elSSN: 2444-1961

Ediciones Universidad de Salamanca - CC BY-NC-ND 
juvenil se refiere. De su producción se han traducido El tiempo de los deseos secretos (M.: Alfaguara, 1991), por J. Mlejnkova y A. Ortiz, y Carolina: una breve biografía (Santa Marta de Tormes: Lóguez, 2007), por Laura Llamas a partir del alemán.

El novelista y dramaturgo Ivan Klíma (1931) pasó varios años de su adolescencia confinado en el campo de concetración de Terezín, por su condición de judío. Durante su vida adulta sufrió el ostracismo y su obra estuvo prohibida en su país durante más de veinte años. Se convirtió en una de las figuras más prominentes de la literatura clandestina checa y mantuvo estrechos lazos con Václav Havel en la Revolución de Terciopelo de 1989, en una época en que se le consideró el portavoz del movimiento disidente checo, si bien tras la elección de Havel como presidente se retiró de la vida pública y se concentró en la escritura. Es autor de una treintena larga de libros que incluye novelas, relatos, obras de teatro y ensayo traducidas a más de treinta lenguas. Contamos con sendas traducciones de Amor y basura: la de C. Janés y J. Stancel (M.: Debate, 1991) y la de Judit Romeu (B.: Acantilado, 2007), además de la catalana, Amor i brossa (B.: Edicions 62, 2002), por Kepa Uharte. K. Uharte es otro de los grandes traductores de literatura checa, tanto al castellano como al catalán. El argumento de esta obra gira en torno a un escritor judío convertido en barrendero por la represión soviética. El protagonista elabora una exégesis de la vida y obra de Kafka, con quien parece identificarse. Por otra parte, en la obra se confronta el amor matrimonial hacia su esposa y la pulsión del adulterio hacia su amante. También contamos con una de las obras más conocidas de Klíma, El juez juzgado (Debate, 1993), por František Bates, un thriller político que indaga en las razones por las que ciudadanos supuetamente íntegros acabaron colaborando con el régimen opresor durante el dominio soviético. En la República Checa no se publicó hasta 1994, pero ya en 1976 había circulado en forma de samizdat. En 2010 se publicaron las versiones castellana y catalana que Dolors Udina hizo a partir del inglés de una recopilación de veinticinco textos de diverso origen -artículos, conferencias y evocaciones- que Klíma escribió en diversas épocas, tanto en inglés como en checo: El espíritu de Praga (Acantilado) y L'esperit de Praga (Quaderns Crema). Finalmente, podemos reseñar la publicación de un opúsculo, en edición bilingüe catalana e inglés, con la conferencia impartida en el Centro de Cultura Contemporánea de Barcelona el 10 de marzo de 2008, Sobre la propaganda (B.: CCCB, 2009), en traducción al catalán por J. Romeu Labayen.

Otro autor repudiado fue J. Putík (1923-2013), que participó en la resistencia contra los nazis y fue encarcelado en el campo de concentración de Dachau. Durante el periodo de represesión soviética fue distribuido en samizdat y publicado en el exilio. De hecho, su obra más conocida solo pudo ser leída, en un principio, en samizdat (en 1982), si bien su publicación posterior le valió el premio Egon Hostovský en 1987. Dicha novela ha sido traducida con el título de El hombre de la navaja barbera (B.: Península, 1992), por Roser Berdagué, y en ella se reconstruye, a través de la visión de un testigo parcial que hace la función de editor, la biografía de un barbero de provincias

LUIS PEGENAUTE La narrativa checa en España desde 1975: presencias y ausencias 
que proyecta una mirada irónica sobre el destino, presentando así una visión tragicómica o grotesca de la existencia. Es la única obra de Putík traducida en España o al castellano. No contamos con traducción de sus muy relevantes diarios, que cubren los años 1968-70 y 1971-89, ni tampoco de otras obras importantes, como Smrtelná neděle [Domingo mortal, 1967], en la que se relata la relación sentimental que establece con su psiquiatra, una mujer que, tras haber permanecido en un campo de concentración y casarse con un hombre de éxito, experimenta un intento frustrado de suicidio.

De D. Hodrová (1946) -cuya obra también fue prohibida en su país- solo contamos con la versión de la novela Cuerpo y sangre, en la que se relata la vida de la ciudad de Praga desde la Primera Guerra Mundial hasta mediados de los 80, en la versión hecha por traductor desconocido para Seix Barral en 1993. Esta novela forma parte de una trilogía -Tryznivé město [La ciudad doliente]-, que se publicó de forma conjunta en 1999, pero las dos restantes, Kukly [Crisálida] y Théta, no se han traducido.

Un autor que podríamos denominar «clásico» es el judío Jiří Weil (1900-1959), que, en su juventud durante sus años filocomunistas, residió en la Unión Soviética, donde ejerció como traductor y periodista hasta que fue deportado a Kazajistán, víctima de las purgas emprendidas por Stalin tras el asesinato en 1934 del líder político Sergey Kirov, supuestamente por orden del Comisariado del Pueblo para los Asuntos Internos. Tras su regreso a Praga, Weil dejó constancia de aquellas purgas en su novela Moskva-hranice (1937), traducida mucho tiempo después como Moscú: frontera (Guadarrama: Ediciones del Oriente y del Mediterráneo, 2006) por Eduardo Fernández Couceiro. Weil fue objeto continuo de persecución, primero durante la ocupación nazi, que le obligó a vivir en la clandestinidad; posteriormente, durante el régimen comunista instaurado en Checoslovaquia, que le consideraba «enemigo del pueblo». En 1949 publicó uno de los mejores retratos de la penosa situación vivida por los judíos bajo la ocupación nazi, traducido mucho tiempo más tarde como Vida con estrella (M.: Impedimenta, 2017) por Patricia Gonzalo de Jesús. Weil también es conocido por una novela publicada en 1959, tras quince años de preparación, que fue traducida al castellano como Mendelssohn en el tejado (Impedimenta, 2017) por Diana Bass, y en la que presenta diversas historias entrecruzadas bajo el telón de fondo de la ocupación nazi, entrelazando ficción y hechos históricos. Ambas fueron traducidas al catalán por Jaume Creus para la editorial Viena: Viure amb una estrella (2017) y Mendelsshon és a la teulada (2015).

También sufrió persecución H. M. Kovály (1919-2010), quien tras sobrevivir a los campos de concentración judíos vio cómo su marido, que era ministro de Comercio Exterior, fue injustamente sometido a la pena capital por parte de las fuerzas comunistas en el infame juicio de Slánský, orquestado por Stalin contra el liderazgo ejercido por miembros judíos del Partido y contra aquellos que consideraba elementos desleales entre las filas comunistas de Centroeuropa por su alineamiento con el dirigente yugoslavo Josip Broz Tito. Cuando en 1969 las tropas soviéticas invadieron Praga, se

Luis PEGENAUTE La narrativa checa en España desde 1975: presencias y ausencias 
exilió con su segundo marido en EE. UU., donde permaneció hasta 1996, año en que regresó a su país. De su producción cabe destacar sus memorias, Bajo una estrella cruel: una vida en Praga (1941-1968) (B.: Libros del asteroide, 2013), por Luis Álvarez Mayo desde el inglés.

De aquella generación de escritores perseguidos por el régimen comunista hay alguno medianamente relevante del que no se ha llegado a traducir nada; tal es el caso, por ejemplo, de la también historiadora del arte Vĕra Linhartová (1938), que tras exiliarse en París en 1968 ha escrito en francés un buen número de volúmenes en prosa y verso, si bien es es igualmente cierto que tampoco se ha traducido a otros medianamente relevantes que no fueron purgados por el gobierno, como Jan Otčenášek (1924-1979), o que eran abiertamente simpatizantes, como Vladimír Paral (1932). Una excepción entre estos últimos ha sido Ladislav Fuks (1923-1994), pues K. Uharte ha traducido al catalán, L'incinerador de cadàvers (B.: La Guineu, 207), una novela que describe la deformación moral de un ser mediocre durante la ocupación nazi y cuya ambientación y tratamiento psicológico de los personajes está en consonancia con la mayor parte de la obra de su autor.

\section{DIARIOS Y MEMORIAS}

Tal y como señala Fialová (s.f., s.p.), en la literatura escrita con posterioridad a 1989 destaca la proliferación de diarios y memorias presentados por autores que deseaban describir su existencia de la manera más fiel posible, sin la necesidad de recurrir a efectistas juegos estilísticos. En este ámbito autobiográfico encontramos algunos precedentes, como el de Ota Pavel (1930-1973), periodista deportivo y escritor judío, a quien le fue diagnosticado un trastorno bipolar en 1964 mientras cubría los Juegos Olímpicos de invierno que se celebraban en Innsbruck. La editorial barcelonesa Sajalín ha publicado dos de sus obras más conocidas: en Cómo llegué a conocer a los peces (2012), por P. Gonzalo de Jesús, rememora distintos episodios de su vida ligados a su pasión, la pesca; en Carpas para la Wehrmacht (2015), por K. Uhalde, presenta una serie de relatos autobiográficos en los que destaca la presencia de su padre. Las versiones originales de estas dos obras datan, respectivamente, de 1971 y 1974. Otro precedente es el del poeta Jaroslav Seifert, quien en 1979 había publicado un libro que recopilaba, de forma fragmentaria y abundando en la anécdota, unas memorias en las que repasaba su propia vida, la de Praga y la de todo el país. En castellano se publicó al año siguiente de su concesión del Premio Nobel de literatura, con el título de Toda la belleza del mundo. Historias y recuerdos (Seix Barral, 1985), por M. Zgustová y Elena Panteleeva.

En los autores que escriben con posterioridad a 1989 encontramos que en muchos casos habían sufrido persecución por parte de las fuerzas soviéticas y que 
deseaban dejar testimonio de la realidad que les había tocado vivir. Entre los autores a los que nos estamos refiriendo, posteriores a los dos ya citados, podemos mencionar, por ejemplo, al escritor y traductor Jan Zábrana (1931-1984), del que F. Valenzuela ha traducido Toda una vida (B.: Melusina, 2010), una selección de los pasajes más interesantes de su diario publicado originalmente en 1992 y que Antonio José Ponte calificó en Letras libres (30-11-2011) como «la venganza de un escritor condenado a la muerte civil». De todos modos, se quedaron sin traducir, por ejemplo, Paměti [Memorias, 1992-1994] del crítico literario y filósofo Václav Černý (1905-1987), apreciado hispanista que tradujo al checo a Unamuno, Gasset y Cervantes, o Teorie spolehlivosti [Teoría de la fiabilidad, 1994] del poeta y ensayista Ivan Diviš (1924-1999), además de muchas otras contribuciones de autores que practicaron esta literatura «testimonial», como Jan Hanč (1916-1963), Sergej Machonin (1918-1995), Josef Hiršal (1920-2003) o Bohumila Grögerová (1921-2014). A mediados de los años 90 la producción de estos diarios remitió, si bien alcanzó gran notoriedad la publicación en 2003 de los Diarios que el guionista y director de cine Pavel Juráček (1935-1989) escribió entre 1959 y 1974 y que continúan inéditos en España.

\section{AUTORES POSMODERNOS}

También según Fialová (s.f., s.p.), otra de las corrientes más significativas dentro de la narrativa producida con posterioridad a 1989 la encontramos representada en una serie de autores que cultivaron un tipo de literatura que podríamos calificar de «posmoderna» por su uso de una nueva mímesis realista; su nuevo tratamiento del autor, el narrador, los personajes y el lector; la confusión temporal; el recurso a la metaficción, la parodia o la alegoría; además de la eventual defensa de un hedonismo artístico. Uno de los exponentes más tempranos fue el psicólogo, novelista y poeta Jan Křesadlo (1926-1995), quien practicó este tipo de literatura en el exilio, si bien no ha sido traducido. A lo largo de los años 90, el exponente por antonomasia de esta corriente fue el periodista, novelista y dramaturgo Jiři Kratochvil (1940), el cual ha sido ganador de diversos premios literarios, como el Tom Stoppard (1991), el de los libreros checos (1993), el Egon Hostovský (1996), el Karel Čapek (1998) o el Jaroslav Seifert (1999), aunque en los inicios de su carrera hubo de ser distribuido clandestinamente mediante el sistema del samizdat. De la quincena de novelas que ha escrito, solo se han traducido al castellano tres, todas ellas publicadas por Impedimenta: En mitad de la noche un canto (2010), por P. Gonzalo de Jesús, y La promesa de Kamil Modrácek (2013) y Buenas noches, dulces sueños (2017), por Elena Buixaderas. La primera de ellas, que ya había sido traducida por C. Janés y J. Stancel con el título de Canto en medio de la noche (M.: Anaya y Muchnik, 1992), constituye una fábula sobre la vida en Checoslovaquia -más en particular, en la ciudad natal de Kratochvil, Brno- tras la

Luis PEGENAUTE La narrativa checa en España desde 1975: presencias y ausencias 
invasión soviética, constituida por dos historias paralelas de dos hermanos, contadas por ellos mismos. En la segunda obra referida, una novela de tintes policiacos y políticos que tiene también mucho de parábola de humor negro y que parece haber sido inspirada en La promesa de Friedrich Dürrenmatt, así como en el relato Se habla ruso de Nabokov, Kratochvil vuelve a ambientar la trama, como en tantas otras ocasiones, en el opresivo ambiente estalinista de Brno; en este caso, para describir una venganza un tanto melodramática. En la tercera novela, realidad e imaginación se entremezclan, dibujando un retrato de la desolada posguerra europea a través de las peripecias de dos amigos que emprenden la búsqueda de un misterioso personaje que tiene en su poder una medicina que podría salvar la vida de muchos ciudadanos.

La obra en prosa del novelista, poeta y traductor Michal Ajvaz (1949) ha sido calificada en ocasiones como buena representante del «realismo mágico» checo por el uso de la fantasía en sus historias, ambientadas en entornos que aparecen representados de forma misteriosa, como Praga en Druhé město [La otra ciudad, 1993] o como diversas ciudades europeas en Cesta na jih [Viaje al sur, 2008]. Ninguna de ellas ha sido traducida en España. También estaba ambientada en el espacio mágico de Praga la obra de D. Hodrová, a la que ya hemos hecho referencia. Del poeta, novelista y dramaturgo Petr Stančík (1968) contamos con El molino de momias: el descubrimiento revolucionario del comisario Durman (B.: Tropo, 2016), por Daniel Ordóñez. En esta novela, ambientada en la Praga de 1866, con la guerra austro-prusiana de telón de fondo, y que le valió el Premio Magnesia Litera en 2015, Stančík presenta la persecución a la que somete el comisario Durman a un asesino en serie. Si bien no se le ha traducido en España, un caso particular fue el del crítico literario y novelista Vladimir Macura (1945-1999), pues supo respetar las formas genéricas de la novela histórica, pero entremezclando ficción y realidad, como en la tetralogía Ten, který bude [El que será, 1999].

Es destacable la obra de Patrik Ouředník (1957), escritor y traductor de autores como Rabelais, Jarry, Queneau, Beckett, Michaux o Vian, los cuales dicen mucho de su interés por la experimentación con el lenguaje, tal y como queda atestiguado en sus ensayos. De la media docena de novelas que ha publicado se han traducido dos: Europeana: una breve historia del siglo Xx (Salamanca: Tropismos, 2005) e Instante propicio (B.: Melusina, 2007), en ambos casos por K. Uharte. En la primera de ellas, Ouředník nos ofrece su peculiar visión de las contradicciones en la historia del siglo $X X$, demostrando que nada esencial cambió a lo largo de la centuria y que no existe un único punto de vista a la hora de describirla. En la segunda, adapta libremente una experiencia anarquista desarrollada en 1890 en Brasil para describir cómo la concepción de una utopía puede agotarse en sus propios argumentos retóricos.

LUIS PEGENAUTE La narrativa checa en España desde 1975: presencias y ausencias 


\section{ALGUNOS AUTORES DE LOS AÑOS 90}

En la segunda mitad de los 90 destacaron algunos novelistas que adoptaban un tono más íntimo para reflejar la disposición mental de los protagonistas, a menudo afligidos y solitarios, así como el estado de la sociedad checa. Es el caso, por ejemplo, de Zdeněk Zapletal (1951), Jan Balabán (1961-2010), Jiří Hájičck (1967) o Emil Hakl (1958). De todos ellos, tan solo ha sido traducido el último, y en una sola ocasión: De padres e hijos (B.: Melusina, 2008), por K. Uharte. Esta contribución, la más conocida de este poeta y novelista, fue llevada al cine por Vladimir Michálek en 2007. En ella, un biólogo retirado y su hijo en la cuarentena charlan incesantemente sobre política, la familia y el mundo que les rodea durante sus paseos por los parques y suburbios de Praga, ofreciendo una visión íntima de la vida de estos dos personajes.

Una de las voces más distintivas y particulares de la nueva narrativa checa ha sido la del poeta, novelista y periodista Jáchym Topol (1962), hijo del poeta y dramaturgo Josef Topol, y cuya obra poética hubo de ser distribuida en un primer estadio en forma de samizdat, tras haber firmado la Carta 77 con tan solo quince años de edad. Adquirió gran popularidad en su país con la publicación de Sestra [Hermana] en 1994, que fue considerada por la crítica como la gran novela checa de la década y en la que abordaba los grandes problemas de la sociedad del momento, abocada a una situación de caos tras la pérdida de los valores tradicionales. En ella hacía alarde de una particular percepción del mundo y el lenguaje a través de un tratamiento formal muy experimental. En España, la editorial Lengua de Trapo ha publicado tres novelas posteriores, todas ellas traducidas por K. Uharte. En Misiones nocturnas (2007) se relata cómo dos hermanos se ven obligados a marcharse al pueblo de su abuelo tras la invasión de Praga por parte de las fuerzas del Pacto de Varsovia en 1968, así como los esfuerzos del mayor por aparentar una aparente normalidad para no perjudicar la ilusión del más joven. En Gárgaras con alquitrán (2008) se nos presenta también a dos hermanos, en esta ocasión recluidos en un orfanato regido por unas monjas igual de autoritarias que las fuerzas represoras soviéticas. En palabras de Rafael Narbona para El cultural (27-02-2009), en esta obra Topol «nos muestra la transformación que se opera en la condición humana, cuando la opresión asfixia a la conciencia y no cabe otro planteamiento que sobrevivir un día más». Finalmente, en Por el país del frío (2013) un narrador anónimo que se presenta como natural de Terezín -ciudad que sirvió como campo de concentración nazi- emprende un viaje en tren que le hará pasar por Praga hasta llegar a Minsk y en el que va acompañado de diversos personajes, con los que revive la historia reciente de Europa. Se trata, además, de un viaje interior en el que el narrador se plantea si es más conveniente enterrar el pasado o mantenerlo vivo para que no pueda volver a repetirse.

Entre los escritores más populares en el país en las dos últimas décadas del siglo XX se encuentra Michal Viewegh (1964), autor de una veintena larga de obras, de las

Luis PEGENAUTE La narrativa checa en España desde 1975: presencias y ausencias 
que se han traducido La educación de las chicas en Bohemia (M.: Metáfora, 2000), por F. Valenzuela, y Fuera de juego (M.: Maeva, 2010), por K. Uharte. La trama de la primera de ellas, publicada en checo en 1994 y que vendió medio millón de ejemplares en la República Checa, gira en torno a las vicisitudes de un escritor -trasunto del propio autor- que es contratado por un mafioso de Praga para que dé clases de escritura creativa a su hija, sumida en una depresión tras un desengaño amoroso. En la segunda describe la vida de un grupo de antiguos compañeros de clase, desde su adolescencia hasta que alcanzan la cuarentena. La perspectiva sobre la vida en la nueva sociedad y sobre las oportunidades y congojas que esta lleva implícita fue también tratada por autores como Jan Jandourek (1965) o Bohuslav Vaněk-Úvalský (1970), los cuales no han sido traducidos en España. Sí que lo ha sido el novelista y traductor Miloš Urban (1967), autor de una producción literaria que podría calificarse como nueva novela gótica y posmoderna y que ha sido publicado por Ediciones B -Las siete iglesias (2005) y Lord Mord (2009)- y por El Andén -La lengua de Santini (2007) y El mago del agua (2008)- en traducción de K. Uharte. Por lo general, sus historias están asociadas a un espacio específico, en el que se desarrollan misteriosos rituales y en el que resuenan ecos de pérdida y destrucción. Así, por ejemplo, en Las siete iglesias, una de sus novelas más conocidas, se inspira en la novela gótica anglosajona para presentar una obra ambientada en Praga, en la que el protagonista, un policía apasionado por la historia y arte medievales, ha de resolver los crímenes cometidos en siete iglesias de la ciudad.

También ha sido muy popular Petr Šabach (1951-2017), a quien se considera heredero literario de $\mathrm{H}$. Hašek y B. Hrabal, con obras como La mierda arde (2016) o Documento de identidad (2018), en ambos casos en versión de K. Uharte para la madrileña Huso. La primera de ellas, constituida por dos relatos y una novela corta, es un buen reflejo de la aproximación amargamente humorística del autor a la realidad. Tras su publicación en checo en 1994, fue objeto de numerosas reediciones. La breve novela incluida en el volumen sirvió de base argumental para dos películas de Jan Hřebejk. También fue llevada a la pantalla Documento de identidad, en este caso por Ondrej Trojam. En esta novela, publicada en su lengua original en 2006, se relata la trayectoria de cuatro adolescentes desde que cumplen quince años y reciben sus documentos de identidad hasta que llegan a la mayoría de edad y han de incorporarse al ejército, describiendo el desconcierto de su existencia vital en un sistema totalitario.

\section{NOVELISTAS FEMENINAS Y FEMINISTAS}

En este apartado resultan más destacadas las ausencias que las presencias. A comienzos de los años 90 se dio en el país un auge de la escritura feminista, con autoras que adoptaban un posicionamiento ideológico claramente combativo, como es el caso de Carola Biedermannová (1947-2008) o de Eva Hauserová (1954). En otros casos, se

LUIS PEGENAUTE La narrativa checa en España desde 1975: presencias y ausencias 
limitaron a dejar testimonio de la percepción femenina del mundo, sin adoptar una actitud tan marcadamente política, como Alexandra Berková (1949-2008), Zuzana Brabcová (1959-2015), Svatava Antošová (1945) o Věra Nosková (1947). Sí que ha sido traducida, sin embargo, Tereza Boučková (1957), de la que contamos en castellano con El año del gallo: diario de una madre adoptiva (M.: Xorki, 2016), por E. Buixaderas. Se trata de una confesión en forma de diario de una mujer que acaba por admitir el fracaso de su proyecto familiar -que incluía la adopción de dos niños de etnia gitana, a los que ve abocados a la delincuencia- y que busca una salida a su crisis personal y creativa. Con la llegada del nuevo milenio, surge una nueva generación de escritoras que no tardan en destacar en la escena literaria. Así, por ejemplo, fue muy celebrado el debut de Petra Hůlová (1979), Pamět’ mojí babičce [En memoria de mi abuela, 2002], que fue uno de los libros más leídos de la década en su país, en el que describe la vida de varias generaciones de mujeres mongolas en el entorno tradicional de la vida familiar en la estepa. También han descollado la novelista, dramaturga y guionista Petra Soukupová (1982), ganadora de los premios Jirí Orten (concedidos al mejor autor con menos de treinta años) en 2008 y el Magnesia Litera al mejor libro del año en 2010 o Jana Šrámková, que también ganó el Premio Orten en 2009 por su debut literario, la novela Hruškadóttir [Laberinto], publicada el año antes.

\section{LITERATURA DE VIAJES Y BÚSQUEDA DE ESPACIOS EXÓTICOS}

Cabe mencionar también la presencia de diversos novelistas que buscan escenarios fuera del contorno nacional, ya sea en países cercanos o en entornos exóticos, si bien pocos de ellos han sido traducidos en España. Así, por ejemplo, no contamos todavía con nada del escritor, dramaturgo y guionista Jaroslav Rudiš (1972), que fue merecedor en 2002 del premio Jiři Orten por Nebe pod Berlínem [El cielo bajo Berlín], una novela en la que se entremezclan diversas historias desarrolladas en esta ciudad, sobre todo en su metro, y que sirve de escenario para las vivencias de un grupo de rock. Otras aportaciones de Rudiš también están ambientadas en Alemania y otros espacios europeos. Hůlová, tras haber enmarcado en Mongolia la acción de la ya referida En memoria de mi abuela, situó su obra Stanice Tajga [Estación taiga, 2008] en Siberia, al igual que haría Martin Ryšavý (1967) con Cesty na Sibiř [Carreteras a Siberia, 2008]. Por su parte, la periodista, escritora e hispanista Markéta Pilátová (1973) ha ambientado varias de sus novelas en Latinoamérica, aprovechando su experiencia vital de cinco años de estancia en Brasil y Argentina: así, por ejemplo, en Má nejmilejší kniha [Mi libro favorito, 2009], en Mis ojos te llevarán a casa (2012) o en Tsunami blues (2016), las cuales han sido traducidas por K. Uharte para la editorial Baile del sol (Tegueste). Si el escenario de Mis ojos te llevarán a casa es São Paulo, la acción de Tsunami blues

Luis PEGENAUTE La narrativa checa en España desde 1975: presencias y ausencias 
transcurre en la República Checa, Tailandia y Cuba. Hana Androniková (1967-2011), por su parte, buscó la jungla sudamericana y las praderas de Norteamérica como escenario de Nebe nemá dno [El cielo no tiene fondo 2010], novela inspirada en sus propias experiencias de lucha contra el cáncer. La presencia del territorio extranjero se deja sentir también en las novelas de escritores pertenecientes a generaciones anteriores, que reflexionan sobre el sentimiento de pérdida y el trauma de la emigración forzada, como el dramaturgo, novelista y director de cine Edgar Dutka (1941), el novelista y ensayista Lubómir Martínek (1954) o el escritor Ivan Landsmann (1949-2017).

\section{LA NOVELA HISTÓRICA}

La novela histórica ha contado tradicionalmente con un importante favor por parte del público checo. Se trata de autores que, en la mayor parte de los casos, no han llegado a España. Así, por ejemplo, Jiř́ Šotola (1924-1989) o Vladimir Körner (1939), los cuales también descollaron como dramaturgos. Idéntica situación encontramos con Ludmila Vaňková (1927), autora de la tetralogía Lev a rưže [El león y la rosa, 19771987] o, más tardíamente, Vlastimil Vondruška (1955), historiador y novelista, autor de diversos trabajos científicos sobre la historia de la cultura material y de un total de cuarenta thrillers ambientados en época medieval, fundamentalmente.

Es también destacable en el presente siglo el intento de novelar la historia reciente, con diversas obras ambientadas en los años de la Segunda Guerra Mundial y centradas, principalmente, en el Holocausto y la cuestión judía. Tal es el caso, por ejemplo, de H. Androniková, ya mencionada, con Zvuk slunečních hodin [El sonido del reloj de sol, 2001]; Magdaléna Plaztová, con Aaronuiv skok [El salto de Aaron, 2006], o autores más consolidados, como J. Škvorecký, al que ya nos hemos referido, y el novelista, dramaturgo y guionista Arnošt Lustig (1926-2011). Este último, que fue confinado en diversos campos de concentración por su condición de judío, se significó en contra del régimen comunista y se exilió en Israel, Yugoslavia y finalmente, en EE. UU., antes de regresar a su país en 2003. En el año 2009 recibió el Premio de literatura a la labor de toda una vida, concedido por la Academia Norteamericana de las Artes y las Ciencias, así como una nominación para el Man Booker. Fue candidato en varias ocasiones al Nobel de literatura. Enrique García y Aurora Fernández se ocuparon ya tempranamente de Esperanza (Praga: Artia Paraha, 1963), conjunto de diversas historias ambientadas en el campo de concentración de Theresienstadt. Posteriormente, Elsa Mateo tradujo -a partir del inglés- Sueños impúdicos (Seix Barral, 1990), conjunto de tres novelas breves ambientas en la Praga de los últimos años de la Segunda Guerra Mundial. Ya en el presente siglo, K. Uharte ha traducido Ojos verdes (Galaxia Gutenberg, 2006), en la que se narra la dramática experiencia de una adolescente judía obligada a prostituirse en un campo de concentración y P. Gonzalo de Jesús, Una canción por Katerina

Luis PEGENAUTE La narrativa checa en España desde 1975: presencias y ausencias 
Horovitzorá (Impedimenta, 2014), una historia sobre el angustioso engaño al que son sometidos unos acaudalados judíos que van a ser supuestamente intercambiados por militares alemanes de alta graduación y que, en palabras de M. Montmany para El cultural (19-06-2012), «confronta el bárbaro discurso nazi con el aplomo de aquellos que se empeñan en seguir siendo humanos». Recientemente se ha publicado en catalán y castellano la obra de Petr Ginz (1928-1944), Diari de Praga (1941-1942) (Acantilado, 2006), por K. Uharte, y Diario de Praga (1941-1942) (Libros del asteroide, 2009), por Juan de Sola. Ginz fue un adolescente que estuvo recluido y falleció en el campo de concentración de Theresiendstat y cuyo diario escribió antes de ser deportado. El diario, que ha sido comparado con el de Anna Frank, estuvo mucho tiempo perdido hasta que fue recuperado y publicado por su hermana Eva.

Según nos recuerda Fialová (s.f., s.p.), algunos de los escritores más jóvenes abordaron desde perspectivas temáticamente novedosas los años de la posguerra, reconstruyendo aquel periodo desde otra perspectiva: así, por ejemplo, Kateřina Tučková (1980), en una obra que no ha sido traducida, Vyhnání Gerty Schnirch [La expulsión de Gerta Schnirch, 2009], describe el punto de vista de aquellos alemanes que eran inocentes de los crímenes cometidos por las fuerzas nazis. Radka Denemarková (1968), por su parte, en una novela que le valió el Premio Magnesia Litera en 2007, El dinero de Hitler (Galaxia Gutenberg, 2015), traducida por E. Buixaderas, narra el regreso a su pueblo natal de una anciana judía que intenta recobrar todo aquello de lo que había sido despojada sesenta años atrás, tanto material como espiritualmente, por parte de sus propios compatriotas.

Los años de sometimiento al régimen comunista fueron retratados por numerosos escritores, ya fuera bajo la forma de memorias o de ficción. Así, por ejemplo, Lenka Reinerová (1916-2008), escritora de origen judío y de expresión alemana, describe en Todos los colores del sol y de la noche (Libros del asteroide, 2009), por Juan de Sola, los quince meses que estuvo presa en Praga entre 1952 y 1953, prestando particular atención a los delirantes interrogatorios que tuvo que soportar. Sin embargo, en muchos casos no contamos con traducciones. Así, por ejemplo, del novelista, dramaturgo y guionista Jan Novák (1953), que escribe tanto en checo como en inglés y se autotraduce entre ambas lenguas. Entre las obras más conocidas de Novák se cuenta Zatim dobrý [Hasta ahora, bien, 2004], que narra las actividades de resistencia armada contra los comunistas por parte de los controvertidos hermanos Mašín y que fue galardonada con el Premio Silesia en 2005. En su siguiente novela, Děda [Abuelo, 2007], describió la historia de una familia que perdía su granja tras el llamado Golpe de Praga, cuando en febrero de 1948 los comunistas accedieron al poder. La cuestión de la colectivización forzada de la propiedad privada fue también tratada por Jiří Hájiček (1967) en Selský baroko [Pueblo barroco, 2005], una novela de tintes detectivescos y galardonada con el Premio Magnesia Litera. El peso de las antiguas culpas familiares en las generaciones posteriores fue el tema de obras como Milostný dopis klínovým

LUIS PEGENAUTE La narrativa checa en España desde 1975: presencias y ausencias
CLINA

vol. 5-2, December 2019, 121-146

elSSN: 2444-1961

Ediciones Universidad de Salamanca - CC BY-NC-ND 
písmem [Carta de amor en cuneiforme, 2008], el debut literario de Tomáš Zmeškal (1966), de ascendencia congoleña, o Patriarchátu dávno zašlá sláva [El patriarcado de la gloria largamente pasada, 2003], de Pavel Brycz (1968), por el que ganó el Premio Nacional de Literatura. Con la excepción de Reinerová, ninguno de estos autores ha sido traducido en España.

\section{MEMORIA HISTÓRICA Y AUTOBIOGRAFÍA}

Tampoco han sido traducidas diversas obras que adoptan el punto de vista de un niño o un adolescente para describir la realidad, en algunos casos desde una perspectiva semiautobiográfica. Como antecedente muy temprano podemos señalar a Václav Dusĕk (1944), por cuyas novelas suelen desfilar jóvenes marginales proscritos por la sociedad. Las cuatro primeras, publicadas a lo largo de los años 70, están protagonizadas por un personaje, Tadeaš Falk, en el que cabe hallar similitudes con el autor. Muchas de las novelas posteriores usan un marco histórico que se inscribe en el llamado periodo de «normalización» checoslovaco, es decir, aquel comprendido entre la invasión del país por parte de las tropas de Varsovia en 1968 y la apertura liberalizadora iniciada por la Unión Soviética en 1987. Entre estas a las que nos estamos refiriendo cabe mencionar, por ejemplo, Hrdý Budžes [El orgulloso Budž, 1998], de Irena Dousková (1964), una obra que cosechó gran éxito cuando fue adaptada para el teatro y que vio su continuación en Oněgin byl Rusák [Onegin era ruso, 2006]; Osvobozené kino Mír [El liberado cine Mir, 2002], del médico, escritor y humorista Ladislav Pecháček (1940); U útulku 5 [En la casa 5, 2005], del ya referido E. Dutka, el cual obtuvo el Premio Nacional de Literatura en 2005; Na krásné modré Dřevnici [El bello y azul río Dřevnici, 2009], de Antonín Bajaja (1942), conocido por sus novelas de ambientación rural, generalmente localizadas en la Valaquia morava; la trilogía compuesta por Bereme, co je [Tomamos lo que es, 2006], Obsazeno [Ocupado, 2007] y Víme svý [Sabemos el tuyo, 2008], de la poetisa, novelista y periodista Věra Nosková (1947), que ha destacado también como activista defensora del pensamiento crítico y la divulgación del método científico como contraposición a la falsa ciencia y cuya obra describe la vida en la pequeña ciudad en que residió durante los años 60 y 70 . Tampoco se ha traducido nada del escritor y traductor Martin Fahrner (1964), autor de, por ejemplo, Steiner aneb Co jsme dělali [Steiner o lo que hicimos, 2002], novela en la que se narra la historia de una familia común en los años precedentes y posteriores a 1989; ni del periodista, escritor y traductor Jan Balabán (1961-2010), entre cuya producción se encuentra, por ejemplo, Kudy šel anděl [Donde se fue el ángel, 2003], una novela que retrata el deprimente ambiente existencial que en los años 70 rodea a su protagonista adolescente en Ostrava, capital de la región de Moravia-Silesia y ciudad en la que residió el propio Balabán; ni del poeta Pavel Kolmačka (1962), autor de una sola novela, 
Stopy za obzor [Rastros tras el horizonte, 2006], cuyo protagonista intenta conciliar su mundana existencia vital con la meditación en Dios; ni del periodista y escritor Jiř́ Hájíček (1967), autor de la novela Rybí Krev [Sangre de pez, 2012], por la que recibió el premio Magnesia Literaria y en la que se describe la desolación de la protagonista al regresar a la casa de su aldea natal y encontrarse un pueblo muy alejado del que había idealizado en su memoria, acosado, como otros de su entorno, por la construcción de una presa para permitir la instalación de la central nuclear de Temelín.

En los últimos tiempos, la escena literaria checa ha presenciado la publicación de diversas novelas inspiradas en hechos reales, con gran lujo de detalles biográficos, como es el caso de, por ejemplo, Una historia de la luz (Santiago de Compostela: Errata naturae, 2019), aclamada obra de Jan Němec (1981), en traducción de E. Buixaderas, en la que se narra, a medio camino entre la ficción y realidad, la historia de František Drtikol, un fotógrafo de la primera mitad del siglo XX. No han sido traducidas, sin embargo, obras como Medvědí tanec [El baile del oso, 2014], en la que la guionista, periodista y guionista Irena Dousková (1964) describe los últimos años de la vida del escritor Jaroslav Hašek en la pequeña localidad de Lipnice, ni tampoco Básník [Poeta, 2014], de Martin Reiner (1964), que le valió los premios Josef Škvorecký (2014) y Magnesia Litera (2015) y en la que se novela la vida del poeta Ivan Blatný, describiendo sus estancias en diversos hospitales psiquiátricos, a la vez que se traza un panorama de la cultura checa desde el final de la Primera Guerra Mundial hasta 1948.

\section{COLECCIONES DE RELATOS}

La editorial Huso ha publicado muy recientemente, en colaboración con el Ministerio de Cultura de la República Checa, la antología de relatos Lenin, varanos, chicas, hormigón (2018), preparada por el crítico literario Radim Kopač y traducida por K. Uharte, con aportaciones de M. Ajvaz, T. Boučková, D. Čechova, I. Dousková, E. Dutka, E. Hakl, J. Hájiček, J. Kratochvil, Iva Pekárková, P. Placák, P. Šabach, M. Urban y M. Viewegh, es decir, trece de los más renombrados cuentistas actuales. Kopač se encargó también de preparar una Antología de la poesía checa contemporánea (Valencia: Pre-textos, 2012), que ha sido traducida por P. Gonzalo de Jesús. En el apartado de antologías cabe señalar, igualmente, Humor en serio: una antología checa (B.: La Fuga, 2017), que recoge diversos relatos cómicos o absurdos de Kafka, Hašek, Poláček, Herrmann, Rakous, Čapek, Hrabal y Čech sobre el sinsentido de la burocracia, la sinrazón de la guerra y la sociedad industrial, en traducción de Montse Tutusaus, Jorge Seca y M. Zgustová. Una circunstancia un tanto extraordinaria fue la publicación bilingüe -checo y gallego- del volumen de relatos Cen contos ou sexa, un plan incumprido (Santiago de Compostela: USC, 2000) del escritor y actor Jiři Suchý (1931), en traducción realizada por los alumnos del Instituto de Idiomas de Santiago

Luis PEGENAUTE La narrativa checa en España desde 1975: presencias y ausencias 
de Compostela, bajo la dirección de Katerina Vlasakova, pues se trata esta de la única traducción realizada en España de dicho autor.

\section{ALGUNAS AUSENCIAS FINALES}

No hallamos traducciones de autores consagrados, como el poeta, novelista, ensayista y traductor Michal Ajvaz (1949), si exceptuamos el relato incluido en Lenin, varanos, chicas, hormigón; ni del novelista y crítico literario Vladimir Macura (1945-1999); ni de aquellos que, como Václav Kahuda (1965) o Roman Ludva (1966), han practicado ocasionalmente la novela de corte autobiográfico. Tampoco de otros novelistas como Sylvie Richterová (1945), Antonín Bajaja (1947), Lubomír Martínek (1954), Anna Zonová (1962), Michal Šanda (1965), Jiří Hájičck (1967) o Jaroslav Rudiš (1972). Anterior a todos estos fue el músico y escritor Jaroslav Velinský (1932-2012), autor de una prolífica producción en el campo de la ciencia ficción y la novela de detectives. Quizás una de las ausencias más lamentables es la del periodista y escritor L. Vaculk (19262015), redactor del famoso manifiesto Dva tisíce slov [Dos mil palabras, 1972] y activo difusor de literatura en forma samizdat a través de la editorial clandestina Pletlice. En una de sus obras más conocidas, Sekyra [El hacha, 1966], describe a través de los ojos de un alter ego, un periodista que regresa a su pueblo natal en Moravia, la ilusión inicial y la posterior decepción ante la creación de un nuevo Estado. En su aportación más importante, Český snář [La clave de los sueños, 1980], recoge los recuerdos de su vida cotidiana y de compañeros como Václav Havel, Petr Pithart o Milan Uhde en el periodo de «normalización» de finales de los 70.

\section{BIBLIOGRAFÍA}

CuENCA DROUHARD, Miguel José. 2013. «Influencia del polisistema cultural español en la traducción de la literatura checa durante la segunda mitad del siglo XX». Tesis doctoral. Praga: Univerzita Karlova v Prace. https://dspace.cuni.cz/handle/20.500.11956/56902.

FIALOVÁ, Alena. s. f. «Czech Prose since 1989». En Czech Literature Online. https://www.czechlit. cz/en/resources/czech-literature-in-a-nutshell/czech-prose-since-1989/.

FRENCH, Alfred. 1982. Czech Writers and Politics, 1945-1969. Canberra: Australian National University Press.

HERMIDA DE BLAS, Alejandro. 1997. «Literatura checa». En Historia de las literaturas eslavas, ed. por Fernando Presa. Madrid: Cátedra, 245-370.

HERMIDA DE BLAS, Alejandro. 2003. «La difusión en España de las peoqueñas literaturas europeas: el caso checo y eslovaco». En Lenguas y culturas de los países de la Unión Europea, ed. por Fernando Presa. Madrid: GRAM, 155-163.

LUis PEGENAUTE La narrativa checa en España desde 1975: presencias y ausencias 
HERMIDA DE BLAS, Alejandro y Patricia GONZALO DE JESús. 2007. "Translation of Czech and Slovac Literature in Spain: An Approach». En Iberian and Slavonic Cultures: Contact and Comparison, ed. por Beata Elżbieta Cyeszyńska. Lisboa: CompaRes, 185-204.

HERMIDA DE BLAS, Alejandro y Patricia GONZALO DE JESÚS. 2009. «Literaturas checa y eslovaca». En Diccionario histórico de la traducción en España, ed. por Francisco Lafarga y Luis Pegenaute. Madrid: Gredos, 218-221.

HOLÝ, Jiř́. 2008. Writers under Siege: Czech Literature since 1945. Brighton / Portland: Sussex Academic Press.

PORTER, Robert. 2001. An Introduction to Twentieth-Century Czech Fiction: Comedies of Defiance. Brighton / Portland: Sussex Academic Press.

SCHEJBAL, Jan y David UTRERA. 2004. "Les traducciones en txec i eslovac d'obres literàries catalanes i viceversa». Quaderns: Revista de traducció 11: 45-57.

VAVROUŠOVÁ, Petra. 2016. "Censorship of Translated Literature under Franco's Dictatorship: Self-Censorship of Czech Literature». En Politics, Policy, and Power in Translation History, ed. por Lieven D'HULST, Carol O'SULLIVAN y Michael SCHREIBER. Berlín: Frank \& Timme, 135-156.

WoodS, Michelle. 2001. «Original and Translation in the Czech Fiction of Milan Kundera», Translation and Literature 10 (2): 200-221.

WoODS, Michelle. 2006. Translating Milan Kundera. Clevedon: Multilingual Matters.

ZGUSTOVÁ, Monika. 2002. «Literatura checa en España. La bella extranjera». Nueva revista de política, cultura y arte 80: 78-83. https://www.nuevarevista.net/libros/literatura-checa-enespana-la-bella-extranjera/. 